Aquaculture

February 2018, Volume 486, Pages 175-183

http://dx.doi.org/10.1016/j.aquaculture.2017.12.012

http://archimer.ifremer.fr/doc/00415/52599/

(C) 2017 Elsevier B.V. All rights reserved.

\title{
How to genetically increase fillet yield in fish: New insights from simulations based on field data
}

\author{
Fraslin Clémence ${ }^{1,2}$, Dupont-Nivet Mathilde ${ }^{1}$, Haffray Pierrick ${ }^{3}$, Bestin Anastasia ${ }^{3}$, \\ Vandeputte Marc ${ }^{1,2,}$
}

${ }^{1} \mathrm{GABI}$, INRA, AgroParisTech, Université Paris-Saclay, F-78350 Jouy-en-Josas, France

2 Ifremer, Chemin de Maguelone, F-34250 Palavas-les-Flots, France

${ }^{3}$ SYSAAF Section Aquacole, Campus de Beaulieu, F-35000 Rennes, France

* Corresponding author : Clémence Fraslin, email address : marc.vandeputte@inra.fr

\begin{abstract}
:
Fillet yield (i.e. the proportion of edible flesh from a given amount of fish) is a trait of high economic interest for species sold as fillets. Improving it by selective breeding is not an easy task, as it is a ratio trait, which causes mathematical difficulties. It is moreover a specific ratio where numerator (fillet weight) and denominator (body weight) are very strongly correlated (genetic and phenotypic correlations in the range 0.89-0.99). This led some authors to conclude that they have the same genetic and phenotypic basis, precluding selection for improved fillet yield. In this study, we propose to study fillet yield as a component of two traits, fillet weight and waste weight (waste weight = body weight-fillet weight, so the sum of head, bones, fins and viscera weight), which we expect to be less correlated. Using data from 5 batches of fish from 3 species (sea bass, sea bream, rainbow trout), we show that as expected, fillet weight and waste weight are less correlated than fillet weight and body weight (on average, $r A=0.91$ and $r P=0.88$ vs. $r A=0.987, r P=0.981$ ). We used stochastic simulation to generate genotypes and phenotypes of fish using those genetic parameters for fillet weight and waste weight. We simulated 10 generations of selection for increased fillet yield using nine selection indices. Five indices had rather similar performances, residual fillet weight (the residual of the regression of fillet weight to body weight), fillet yield, fillet to waste ratio, restricted selection index (a linear index aimed at improving fillet weight while keeping waste weight constant) and linear index (optimized to improve fillet/waste ratio). With these indices, the average selection gain was $+0.66 \%$ of fillet yield per generation (range 0.30 to $0.95 \%$ using real genetic parameters from 5 fish batches). Selection for the difference between fillet weight and waste weight was $30 \%$ less efficient, while selection for increased fillet weight or increased body weight was 55-65\% less efficient. Selection against waste weight had a null or even negative impact on fillet yield. Factors favorable to higher selection gains are low initial fillet yield, different heritabilities and CVs of fillet weight and waste weight, low genetic correlation and high phenotypic correlation of fillet weight and waste weight. These results suggest that although fillet weight and body weight are strongly correlated and proportional to each other, moderate selection gains on fillet yield are possible. We consider it would be useful to add waste weight in the parameters recorded in future genetic studies on fillet yield.
\end{abstract}




\section{Highlights}

- We estimated genetic parameters of fillet weight and waste weight in fish. We performed stochastic simulations to evaluate gains in fillet yield. Fillet yield can be improved by $0.66 \%$ per generation on average in simulations. Fillet yield, fillet/waste ratio and fillet weight to body weight residuals are good selection indices. Selection for fillet weight or body weight performed poorly to improve fillet yield.

Keywords : Aquaculture, Genetics, Heritability, Selection, Processing yields 


\section{Introduction}

In fish selective breeding programs, the first focus for selective breeding has been growth, generally measured by body weight at a given age (Gjedrem, 2012). Beyond biomass production, fillet yield (fillet weight/body weight ratio) is a highly valuable trait for species sold processed as fillets, as in this case the income comes from the amount of fillet sold. It has been shown that in several cases, growth rate by itself (when it does not imply correlated improvement in feed conversion) may have little economic value (Besson et al., 2016, 2014; Kankainen et al., 2016), but see Janssen et al., 2017). When growth per se is of minor economic importance, increasing the proportion of valuable flesh from a given amount of fish product is in any case expected to increase profitability, as well as to decrease the environmental impact of the production of a given amount of edible fish flesh (Acosta Alba et al., 2015).

However, fillet yield is a lethal trait, impossible to measure on live selection candidates. Thus, this trait is mostly selected through sib selection or indirect selection with correlated traits (e.g. Haffray et al., 2013). Nevertheless, a potential to increase fillet yield by selective breeding seems to exists, as it shows low to moderate heritability ranging from 0.03 to 0.35 (Gjerde et al., 2012; Haffray et al., 2013, 2012; Kause et al., 2007, 2002; Navarro et al., 2009; Nguyen et al., 2010; Powell et al., 2008; Rutten et al., 2005a; Vandeputte et al., 2014). Still, it is well known that estimates of heritability for ratio traits can be highly biased and not predictive of the real genetic gain (Gunsett, 1987).

Selective breeding on a ratio is seen as a problematic issue, which has been studied in many animals (poultry, cattle, mice, rats...). Feed efficiency, measured as feed conversion ratio (FCR), the ratio of average daily feed intake to average daily gain, is among the most important traits to improve in animal production systems. Most studies about selection methods for ratio traits have thus focused on feed efficiency (Famula, 1990; Gunsett, 1984; Lin, 1980; Lin and Aggrey, 2013; Varkoohi et al., 2010). The general conclusion of these studies is that selection on a linear index combining the numerator and the denominator trait is generally more efficient than selection directly on the ratio or on only one of its component traits. Still, direct selection on a ratio can be efficient, as demonstrated in quail for FCR (Varkoohi et al., 2010), or in carp for the body height to body length ratio (Ankorion et al., 1992). This is especially true when the heritability of the numerator and denominator are close to each other, and their correlation is lower than 0.6 (Koerhuis and Hill, 1996). In the case of feed efficiency, the genetic and phenotypic correlations between the numerator (body weight 
gain) and denominator (feed intake) of the ratio are generally mild, and thus studies on selection for ratio traits have generally considered correlations in the range 0.3-0.8 (Gunsett, 1984; Lin and Aggrey, 2013). For fillet yield in fish, the correlation between fillet weight and body weight ranges from 0.93 to 0.99 for the additive genetic correlation and from 0.89 to 0.99 for phenotypic correlation (Gjerde et al., 2012; Haffray et al., 2012; Kause et al., 2007, 2002; Navarro et al., 2009; Nguyen et al., 2010; Powell et al., 2008; Rutten et al., 2005a). These very high correlations and the proportionality of fillet weight and body weight have led some authors to conclude that it was not possible to select for improved fillet yield in fish (e.g. Powell et al., 2008), as it would not be possible to improve fillet weight independently of body weight.

In this study, we challenged this last statement, comparing different selection indices for the improvement of fillet yield in fish. In order to work on less correlated traits describing the same reality, we examined the relationships of two carcass traits: fillet weight and waste weight (defined as waste weight= body weight - fillet weight), which we expected to be less correlated than fillet weight and body weight. Waste as defined here is composed of viscera, head and bones of the fish, and is generally not measured as such in papers dealing with genetic variation of fish fillet traits. We estimated heritability, genetic and phenotypic correlations of fillet and waste weight in five populations from three fish species in order to identify realistic phenotypic and genetic parameter sets. Then, we performed stochastic simulation of selection using different selection indices to determine which indices and combination of parameters gave the best gain in fillet yield.

\section{Materials and methods}

\subsection{Estimation of genetic parameters}

In order to perform simulations of fillet weight and waste weight with realistic values, we first estimated their genetic and phenotypic parameters. The database used was composed of carcass traits recorded during five experiments on three species: sea bass (Dicentrarchus labrax), sea bream (Sparus aurata) and rainbow trout (Oncorhynchus mykiss). All fish used to estimate parameters were from factorial or partly factorial designs, with the pedigree identified by microsatellites genotyping. All families were mixed, in order to minimize the environmental effect common to full siblings or half siblings. The estimations of genetic parameters were performed using an animal model with VCE (version 6.0.2, Groeneveld et 
al., 2010), with specific fixed effects for each population. For sea bass each population had sex and dam batch (corresponding to different subpopulations in the breeding nucleus) as fixed effects. Genetic parameters for sea bass were estimated separately in two batches from the same population, one fed a standard diet with marine ingredients, and the other fed a plant-based diet (Bestin et al., 2014). For sea bream, two datasets were available: one with fish reared in tanks and the other one with fish reared in sea cages. For tank-farmed sea bream, tank (the group was reared in two different tanks) and malformation were used as fixed effects, while only malformation was used for cage-farmed sea bream. For rainbow trout, fixed effects were processing date and filleting operator. Maternal effects were tested in all populations and found non-significant, so they were not included in the model. Descriptive statistics (phenotypic means and standard deviation, adjusted for fixed effects) were computed and heritability $\left(h^{2}\right)$, additive genetic correlation $\left(r_{A}\right)$ and phenotypic correlation $\left(r_{P}\right)$ were estimated for fillet weight and waste weight. Characteristics of each population are reported in Table 1.

\subsection{Stochastic simulations}

\subsubsection{Model used}

The traits simulated were non-trimmed fillet weight $\left(P_{f}\right)$ and waste weight $\left(P_{w}\right)$, which or were correlated with additive genetic correlation $r_{A}$ and phenotypic correlation $r_{P}$. The waste was composed of viscera, head and bones of the fish. The reason for this choice, rather than simulating fillet weight and body weight, was to have less correlated traits than the classically used fillet weight and body weight.

The phenotypes of the numerator $\left(P_{f}\right)$ and denominator $\left(P_{w}\right)$ traits of the ratio in the base population $\left(\mathrm{G}_{0}\right)$ were generated according to an additive polygenic model :

$$
\left[\begin{array}{l}
P_{f 0} \\
P_{w 0}
\end{array}\right]=\left[\begin{array}{l}
\mu_{P f 0} \\
\mu_{P w 0}
\end{array}\right]+\left[\begin{array}{l}
A_{f 0} \\
A_{w 0}
\end{array}\right]+\left[\begin{array}{c}
E_{f 0} \\
E_{w 0}
\end{array}\right]
$$

with $P_{i 0}$ the phenotypic value of an individual for the trait $i$ ( $i=f$ for fillet weight, $w$ for waste weight) in the base population $\left(\right.$ Generation $\left.\mathrm{G}_{0}\right), \mu_{P i 0}$ the phenotypic mean of the trait $i, A_{i 0}$ the additive genetic value of the trait $i$ and $E_{i 0}$ the environmental residual for trait $i$. 
with $\boldsymbol{P}, \boldsymbol{A}$ and $\boldsymbol{E}$ following bivariate normal distributions, $\left[\begin{array}{c}P_{f 0} \\ P_{w 0}\end{array}\right] \sim N_{2}\left(\boldsymbol{\mu}_{\boldsymbol{P}} ; \Sigma_{\boldsymbol{P}}\right)$ with $\boldsymbol{\mu}_{\boldsymbol{P}}=\left[\begin{array}{l}\mu_{P f 0} \\ \mu_{P w 0}\end{array}\right]$ and $\sum_{\boldsymbol{P}}=\left[\begin{array}{cc}\sigma_{P_{f}}^{2} & \sigma_{P_{f} P_{w}} \\ \sigma_{P_{f} P_{w}} & \sigma_{P_{w}}^{2}\end{array}\right],\left[\begin{array}{l}A_{f 0} \\ A_{w 0}\end{array}\right] \sim N_{2}\left(\boldsymbol{\mu}_{\boldsymbol{A}} ; \sum_{\boldsymbol{A}}\right)$ with $\boldsymbol{\mu}_{\boldsymbol{A}}=\left[\begin{array}{l}0 \\ 0\end{array}\right]$ and $\sum_{\boldsymbol{A}}=$ $\left[\begin{array}{cc}\sigma_{A_{f}}^{2} & \sigma_{A_{f} A_{w}} \\ \sigma_{A_{f} A_{w}} & \sigma^{2}{ }_{A_{w}}\end{array}\right]$

$\left[\begin{array}{c}E_{f 0} \\ E_{w 0}\end{array}\right] \sim N_{2}\left(\boldsymbol{\mu}_{\boldsymbol{E}} ; \sum_{\boldsymbol{E}}\right)$ with $\boldsymbol{\mu}_{\boldsymbol{E}}=\left[\begin{array}{l}0 \\ 0\end{array}\right]$ and $\sum_{\boldsymbol{E}}=\left[\begin{array}{cc}\sigma^{2} E_{f} & \sigma_{E_{f} E_{w}} \\ \sigma_{E_{f} E_{w}} & \sigma_{E_{w}}^{2}\end{array}\right]$

Note that under a strictly additive genetic model as considered, $\sigma_{P f=}^{2} \sigma_{A f+}^{2} \sigma_{E f}^{2}, \sigma_{P w=}^{2} \sigma_{A w+}^{2} \sigma_{E w}^{2}$, and that $\sigma_{P f P w}=\sigma_{A f A w+} \sigma_{E f E w}$ under the reasonable hypothesis that $\sigma_{A f E w}=\sigma_{E f A w}=0$ (Lynch and Walsh, 1998). Thus, knowing $\sum_{P}$ and $\sum_{A}$ is enough to determine $\sum_{E}$, and all parameters are determined when the means, phenotypic standard deviations, heritabilities of fillet weight and waste weight are known, together with the genetic and phenotypic correlations between them.

\subsubsection{Simulation of phenotypes}

First, additive genetic values for fillet weight and waste were drawn at random with the above-mentioned bivariate normal distribution in a base population of 100 sires and 100 dams, and 100 breeding pairs were formed at random. $\mathrm{G}_{0}$ Breeding candidates $(\mathrm{N}=1000)$ were generated, each from a randomly drawn breeding pair. The additive genetic and phenotypic values for both traits were simulated for each candidate, making use of equations 1 to 4 below:

$$
A_{f}=\frac{\left(A_{f S}+A_{f D}\right)}{2}+\sigma_{P f} * X_{1} * \sqrt{\frac{h^{2} f}{2}}[1]
$$

With $A_{f}$ the additive genetic value of fillet weight for the candidate, $A_{f S}$ and $A_{f D}$ the additive genetic value of fillet weight for its sire and dam, and $\sigma_{P f} * X_{1} * \sqrt{\frac{h^{2} f}{2}}=X_{1} * \sqrt{\frac{\sigma^{2} A f}{2}}$ the Mendelian sampling term, with $X_{1}$ a random number from the standard normal distribution, and $\sigma_{A f}^{2}$ the additive genetic variance of fillet weight. The phenotypic standard deviation of fillet weight was calculated as $\sigma_{P f}=C V_{f} * \mu_{f(G-1)}$, with $\mu_{f(G-1)}$ the mean of fillet weight in the parental generation $(G-1)$. 


$$
A_{w}=\frac{\left(A_{w S}+A_{w D}\right)}{2}+\sigma_{P w} *\left(r_{A} * X_{1}+X_{2} * \sqrt{1-r_{A}^{2}}\right) * \sqrt{\frac{h^{2} w}{2}}
$$

With $A_{w}$ the additive genetic value of waste weight for the candidate, $A_{w s}$ and $A_{w D}$ the additive genetic value of waste weight for its sire and dam, and $X_{2}$ a second random number from the standard normal distribution.

$$
P_{f}=\mu_{P f 0}+A_{f}+\sigma_{f} * X_{3} * \sqrt{1-h^{2}}
$$

With $P_{f}$ the phenotypic value of the candidate for fillet weight, and $\sigma_{n} * X_{3} * \sqrt{1-h^{2}}$ the environmental residual on fillet weight, with $X_{3}$ a third random number from the standard normal distribution.

$$
P_{w}=\mu_{P w 0}+A_{w}+\sigma_{w} * \sqrt{1-h^{2}{ }_{w}} *\left(r_{E} * X_{3}+X_{4} * \sqrt{1-r_{E}^{2}}\right)
$$

With $P_{w}$ the phenotypic value of the candidate for waste weight, and $X_{4}$ a fourth random number from the standard normal distribution. A sex was randomly assigned to each candidate in generation $\mathrm{G}$ with equal probability of being male or female. The last term of equation [4] is the environmental effect on waste weight, and the environmental correlation $\left(r_{E}\right)$ between fillet weight and waste weight was calculated according to Lynch and Walsh (1998):

$r_{E}=\left(r_{P}-r_{A} \sqrt{h^{2}{ }_{f} * h^{2}}\right) / \sqrt{\left(1-h_{f}^{2}\right) *\left(1-h_{w}^{2}\right)}$

The number of parents at each generation was 200 (100 sires and 100 dams). They were randomly paired to produce 100 full-sib families. Each simulation generated 1000 candidates and an additional 1000 tested offspring in the case of sib selection. At each generation, future broodstock were selected among the candidates using different selection indices (see below), and the mean phenotype for fillet yield of the candidates was computed. For each combination of parameters, 10 generations were simulated, and this was replicated 50 times. 


\subsubsection{Selection indices}

Nine selection indices were tested, in order to compare their relative efficiency in term of gain in fillet yield after ten generations of selection. In the simulation program, these selection indices were used to calculate the estimated breeding values (EBVs) of the candidates to selection. The indices tested were the following:

1) Selection on fillet yield: $I_{Y}=P_{f} /\left(P_{f}+P_{w}\right)$

2) Selection on the ratio of fillet weight to waste weight: $I_{R}=P_{f} / P_{w}$

3) Linear selection index: $I_{L}=b_{f} \cdot P_{f}+b_{w} \cdot P_{d w}$ as proposed by Lin (1980) with coefficients $b_{f}$ and $b_{w}$ derived from selection index theory to maximize the $P_{f} / P_{w}$ ratio, after it was linearized by first order Taylor series expansion. The resulting coefficients $\operatorname{are}\left[\begin{array}{l}b_{f} \\ b_{w}\end{array}\right]=\sum_{\boldsymbol{P}}^{-1} \cdot \sum_{\boldsymbol{A}} \cdot\left[\begin{array}{c}1 / \mu_{P f 0} \\ -\mu_{P f 0} / \mu_{P w 0}\end{array}\right]$.

4) Restricted selection index (Morley, 1955): $I_{R S}=P_{f}+\left(-\sigma_{A_{f} A_{w}} / \sigma^{2}{ }_{A_{w}}\right) P_{w}$ developed when the aim of selection is to improve a trait while keeping the other one constant, in our case improving fillet weight while keeping waste weight constant.

5) Selection on the difference between fillet weight and waste weight: $I_{D}=P_{f}-P_{w}$.

6) Upward selection on fillet weight: $I_{F}=P_{n f}$

7) Downward selection on waste weight: $I_{W}=-P_{w}$

8) Upward selection on body weight: $I_{B}=P_{f}+P_{w}$

9) Selection on regression residuals: $I_{r e s}=P_{f}-a .\left(P_{f}+P_{w}\right)+b$.With $a$ and $b$ the slope and intercept of the linear regression of fillet weight on body weight.

The candidates were ranked using either the candidate's own phenotypic performance for a given index (mass selection) or the performance of slaughtered sibs from the same generation, generated with the same procedure (sib selection). In the case of sib selection, an average index was assigned to each parent as the mean of its tested offspring indices, and each candidate was then assigned the mean index of its parental pair. The mass selection case is not possible in real life, but is meaningful here as the response depends only on selection intensity and genetic and phenotypic parameters, and not on technical parameters such as type (full and 
half-sibs) and number of sibs per family, which influence sib selection response. All candidates were ranked, the best 100 sires and best 100 dams were selected and their phenotypes and additive values for both fillet and waste weight were recorded. Those 100 sires and 100 dams were used to produce the next generation with the same procedure as before. It has to be noted that the phenotypic and genetic parameters of fillet weight and waste weight $\left(P_{f 0}, P_{w 0}, C V_{f}, C V_{w}, r_{P}, r_{A}, h_{f}^{2}, h^{2}\right.$ ) were the only parameters needed to simulate all selection scenarios, even those including ratio traits.

\subsubsection{Comparison of indices in five real situations}

First, in order to compare the different selection indices, a selection was simulated for each index using the genetic and phenotypic parameters estimated from the five real fish populations. Selection was also simulated on an average population, the genetic and phenotypic parameters of which were equal to the mean values of the same parameters in the five populations (Table 2). The simulations were performed either with selection on siblings' performance (sib selection) or on the candidate's performance (mass selection).

\subsubsection{Effects of specific parameters and their combinations}

The next objective of the study was to understand how the different parameters influence genetic gain. For the sake of simplicity, and considering similar rankings of indices between mass and sib selection with the parameters tested (see 3.3.1), simulations were performed only under mass selection. Selection was simulated for the linear index $I_{L}$ and the fillet yield index $I_{Y}$ with only one or two parameters varying while all the others were kept constant at the mean of the average population. The parameters tested were the following:

- Initial fillet yield before selection

- Simultaneous variation of $\mathrm{h}_{\mathrm{f}}$ and $\mathrm{h}_{\mathrm{w}}^{2}(6 \mathrm{x} 6$ combinations $)$,

- Simultaneous variation of $\mathrm{r}_{\mathrm{P}}$ and $\mathrm{r}_{\mathrm{A}}$ (9x8 combinations)

- Simultaneous variation of $\mathrm{CV}_{\mathrm{f}}$ and $\mathrm{CV}_{\mathrm{w}}(5 \times 5$ combinations $)$.

The range of variation of all parameters (Table 2) was defined to cover the range of possible values estimated from the five real fish populations.

\subsubsection{Statistical tests}

The objective of the study was to test different selection methods in order to improve fillet yield. Ten generations of selection were simulated with fifty replicates. Selections indices and parameter combinations (heritabilities, genetic and phenotypic correlations, means and 
coefficients of variation) were compared for their effect on the mean of the gain in fillet yield after ten generations: fillet yield in $G_{10}$ minus fillet yield in $G_{0}$. The genetic gain was thus expressed as the absolute gain in fillet yield (as percent of body weight). Differences between mean gains in fillet yield after ten generations of selection were tested with Z-tests. 


\section{Results}

3.1. Estimation of genetic and phenotypic parameters

Basic statistics and genetic parameters estimation are reported in Table 3. In all cases, fillet weight was highly correlated with waste weight $\left(r_{A}=0.91\right.$ and $r_{P}=0.88$ on average). As expected, fillet weight and body weight were even more correlated, 0.987 on average for the additive genetic correlation and 0.981 for the phenotypic correlation (data not shown).

\subsection{Stochastic simulations}

3.2.1. Comparison of selection indices in the five populations and in the average population

The gain in fillet yield after ten generations of selection (\%fillet yield $\mathrm{G}_{10}-\%$ fillet yield in $\mathrm{G}_{0}$ ), with the nine selection indices, for an average population (as defined in table 2) is shown in Figure 1. For each index, selection was performed either on the candidate's performance (mass selection) or on siblings' performance ( sib selection).

The gain in fillet yield from sib selection was significantly lower than the gain from mass selection, except for downward selection on waste weight for which the difference was not significant. However, the ranking of the nine indices was the same for mass and sib selection.

With mass selection, the gain was significantly higher $(\mathrm{P}<0.05)$ with $\mathrm{I}_{\text {res }}$ than with the three indices $I_{Y}, I_{R}$ and $I_{R S}$. Selection with $I_{L}$ was significantly less efficient than with than the previous four indices, but the difference in yield was small $\left(7.4 \%\right.$ for $I_{\text {res }}, 7.2 \%$ for $I_{Y}, I_{R}$ and $I_{R S}$, and $6.9 \%$ for $I_{L}$ ). With sib selection, $I_{r e s}, I_{Y}, I_{R}$ and $I_{R S}$ gave the same gain in fillet yield $(6.9 \%)$ and were significantly better than $I_{L}\left(6.5 \%\right.$ gain). Selection with $I_{D}, I_{F}$ or $I_{B}$ gave a low, although positive, response. Selection against waste weight $\left(\mathrm{I}_{\mathrm{W}}\right)$ had a negative effect on fillet yield (-0.9\% with mass selection and $-0.7 \%$ with sib selection).

The ranking of the indices was similar in the mean population and in both sea bream populations, as well as in the trout population (see supplementary figure S1). Mean gains were rather different for the sea bass populations. The highest gain in fillet yield was obtained for the plant-based feed sea bass population, with more than $8 \%$ gain using the best five indices $\left(I_{Y}, I_{R}, I_{L}, I_{R S}\right.$ and $\left.I_{r e s}\right)$ either in sib or in mass selection. The lowest gain in fillet yield was obtained for the marine-based feed sea bass population, with gains in the $4.2-4.3 \%$ range for $I_{Y}, I_{R S}, I_{R}$ and $I_{r e s}$, with sib selection, and less than $4 \%$ with mass selection. 
Still, in all cases, the best five indices remained $I_{\text {res }}, I_{Y}, I_{R}, I_{R S}$ and $I_{L}$, and the difference in gain between all these indices was always small ( $0.04 \%$ was the highest difference). The worst gain in fillet yield was obtained under downward selection for waste in all populations, either with sib or with mass selection.

\subsection{Effects of specific parameters and their combinations}

\subsubsection{Fillet weight to waste weight ratio}

The gain in fillet yield when the initial fillet yield was varied and all other parameters remained fixed at their mean value is reported in Figure 2.

The gain in fillet yield was highest when the initial fillet yield was lowest, and decreased with the increase of the ratio. Selection on $\mathrm{I}_{Y}$ gave a significantly higher gain in fillet yield than selection on $\mathrm{I}_{\mathrm{L}}$. This difference tended to decrease when the initial ratio increased, and was not significant when the ratio reached 0.66 .

\subsubsection{Heritability}

The graphic representation gain in fillet yield after ten generations when both $\mathrm{h}_{\mathrm{f}}$ and $\mathrm{h}_{\mathrm{w}}{ }_{\mathrm{w}}$ varied and all other parameters were fixed at their average value is reported in Figure 3. The highest gain was $13.5 \%$ while the lowest gain was $4.5 \%$.

The gain was highest (12\%) when $\mathrm{h}_{\mathrm{f}}$ and $\mathrm{h}^{2}{ }_{\mathrm{w}}$ differed much from each other, and was lowest (4.5\%) when the two heritabilities were close to each other and had low values $(0.15-0.25$, Figure 3). When $\mathrm{h}_{\mathrm{f}}{ }_{\mathrm{f}}$ and $\mathrm{h}^{2}{ }_{\mathrm{w}}$ were equal or close to each other, the highest gain in fillet yield was obtained when both values were high $(0.35$ to 0.45$)$, in which case the gain ranged from $7.5 \%$ to $9.0 \%$.

Gains obtained by direct selection on fillet yield $I_{Y}$ (Figure 3a) and selection with the linear index $I_{L}$ (Figure $3 \mathrm{~b}$ ) varied in a similar direction with changes in heritability, but were significantly different in most cases. When both $\mathrm{h}_{\mathrm{f}}$ and $\mathrm{h}^{2}{ }_{\mathrm{w}}$ were moderate $(0.20-0.30), I_{Y}$ tended to give better results than $I_{L}$, but the difference was not always significant. When $\mathrm{h}_{\mathrm{f}}$ was high (0.30-0.40) and $\mathrm{h}^{2}{ }_{\mathrm{w}}$ was moderate $(0.15-0.30) I_{L}$ gave significantly better gains in fillet yield than $I_{Y}$. When $\mathrm{h}^{2}{ }_{\mathrm{w}}$ was low $(0.15), I_{L}$ was significantly better than $I_{Y}$, whatever the value of $h^{2}$.

\subsubsection{Genetic and phenotypic correlations}

The gain in fillet yield when $r_{A}$ and $r_{P}$ between fillet weight and waste weight varied and all others parameters were fixed at their average value is presented in Figure 4. $r_{A}$ varied from 
0.84 to 0.94 and $r_{P}$ from 0.88 to 0.96 . The combinations when $r_{P}$ was 0.96 and $r_{A}$ was 0.84 , 0.86 and 0.88 were not simulated as the calculation of $r_{E}$ (see 2.2.2, equation [5]) gave a value that was higher than 1 .

The simulated gain was highest when $r_{A}$ was lowest, whatever the value of $r_{P}$. The gain increased significantly with the phenotypic correlation. The highest gain in fillet yield was obtained when $r_{A}$ was lowest (0.84) and $r_{P}$ highest (0.96) (Figure 4).

When $r_{A}$ was close to its average value (0.91), the gain in fillet yield doubled when $r_{P}$ increased from 0.80 to 0.96 . On the contrary, when $r_{P}$ was close to its average value $(0.88)$, the gain became six times lower when $r_{A}$ increased from 0.84 to 0.94 .

Trends were very similar for selection on fillet yield $I_{Y}$ and on the linear index $I_{L}$ but the results were significantly different. When $r_{A}$ was between 0.84 and 0.94 , no matter the value of $\mathrm{r}_{\mathrm{P}}, I_{Y}$ gave significantly better results than $I_{L}$, whereas when $r_{A}$ was $0.96-0.98$ and $r_{P}$ was between 0.8 and $0.88, I_{L}$ was significantly better than $I_{Y}$.

\subsubsection{Coefficient of variation of fillet and waste weight}

The gain in fillet yield when the coefficient of variation of fillet weight and waste weight varied is shown in Figure 5. The highest gain could go up to $25 \%$ (when waste weight had a high CV and fillet weight had a low CV) and the lowest gain was 3.5\%

The highest gain was obtained for $C V_{f}=10 \%$ and $C V_{w}=30 \%$ (Figure 5). When $C V_{w}$ was low, the highest gain (15\%) was obtained for high values of $C V_{f}$. On the contrary, when the value of $C V_{w}$ was high, the highest gain in fillet yield (25\%) was obtained for low values of $C V_{f}$. The inversion of the trend appeared when $C V_{f}=C V_{w}$.

Direct selection on fillet yield $\left(I_{Y}\right)$ and selection with the linear index $\left(I_{L}\right)$ gave a similar trend. When $C V_{f}$ was $10 \%$ or $15 \%$, results were not significantly different between the two selection methods. When $C V_{f}$ was higher than $15 \%$, selection on $I_{Y}$ tended to be significantly more efficient than selection on $I_{L}$ when $C V_{w}$ was high (20\% to $30 \%$ ).

When $C V_{f}<C V_{w}$, the gain in fillet yield was high but came from a decrease in waste weight rather than from an increase in fillet weight. When $C V_{f}>C V_{w}$ the gain in fillet yield was also high, but in this case was linked to an increase in fillet weight. 


\section{Discussion}

The simulations we performed, using parameters from different fish species, clearly show that fillet yield, defined as the ratio of fillet weight to body weight, can be genetically improved by selection. Selective breeding yields a significant, yet generally moderate response $(0.66 \%$ per generation on average, ranging from 0.30 to $0.95 \%$ using real genetic parameters from 5 fish batches). As this gain represents a net profit when fish is processed, this level of response however remains interesting.

Five indices outperformed the others, and these were first regression residuals $\left(I_{\text {res }}\right)$, then fillet yield $\left(I_{Y}\right)$, fillet/waste ratio $\left(I_{R}\right)$, restricted index $\left(I_{R S}\right)$, and then the linear index $\left(I_{L}\right)$. Although there were significant differences of selection response between them, these differences remained generally moderate.

The restricted index (Eisen, 1977; Kempthorne and Nordskog, 1959; Morley, 1955) was developed when the aim of the selection is to improve a trait while keeping the other one constant (in our case, improving fillet weight while keeping waste weight constant). It was previously shown to be equivalent to the linear index and to regression residuals in the context of selection for feed conversion ratio (Kennedy et al., 1993).

The linear index (Gunsett, 1984; Lin, 1980; Lin and Aggrey, 2013), developed to improve selection gain on ratio traits, was not in general more efficient than direct selection on the ratios themselves (fillet yield or the ratio of fillet weight to waste weight) or than selection on regression residuals. In some particular cases studied however, the linear index gave significantly better results than direct selection on fillet yield. This was especially the case when $r_{A}=0.98$ and $r_{P}=0.88$, when $0.15<h^{2}<0.25$ and $h^{2}{ }_{w}=0.32$, when $0.2<h^{2}{ }_{w}<0.25$ and $h_{f}^{2}=0.32$, when $h^{2}{ }_{w}=0.45$ and $h_{f}^{2}=0.32$, and when $C V_{w}>20 \%$ and $\mathrm{CV}_{\mathrm{f}}=22 \%$. Although the differences in gain between the two selection indices were small in absolute values, they could represent a large relative difference, e.g., fillet yield gain was $0.25 \%$ per generation with the linear index vs $0.19 \%$ by direct selection on yield $(-32 \%)$ when $r_{A}=0.98$ and $r_{\mathrm{P}}=$ 0.88. This is not in line with Lin an Aggrey (2013), who demonstrated that the linear index always gave better results than direct selection on the ratio. However, the values of $r_{A}$ and $r_{P}$ tested by Lin and Aggrey ( 0.3 or 0.8$)$ were much smaller than the ones tested here ( 0.80 to 0.98). The reason why they did not test very high correlations between the numerator and the denominator is probably because they worked in the context of selection for feed efficiency, 
where the numerator and the denominator are much less correlated than the component traits of fillet yield. To confirm that this is the source of the discrepancies observed, we used our program to simulate selection trials with the parameters tested by Lin and Aggrey (data not shown), and the linear index was then always more efficient than direct selection on the ratio, as reported in their study.

Previous studies on FCR concluded that the linear index was especially more efficient when the heritabilities of the numerator and of the denominator were different (Gunsett, 1984; Koerhuis and Hill, 1996; Lin and Aggrey, 2013), which was also apparent in the present study. However, in the five real fish populations we tested, $\mathrm{h}_{\mathrm{f}}{ }_{\mathrm{f}}$ and $\mathrm{h}_{\mathrm{w}}{ }_{\mathrm{w}}$ were very close to each other ( 0.02 to 0.07 difference), and in this case $I_{L}$ was generally a little less efficient than $I_{Y}$.

Selection on the difference between fillet weight and waste weight, upward selection on fillet weight or upward selection on body weight showed poorer performance than the other indices, in accordance with Lin and Aggrey (2013).

In this study, $h_{f}^{2}$ and $h^{2}{ }_{w}$ estimated in the five fish batches were low to moderate and ranged between 0.23 and 0.42 for $h_{f}^{2}$ and between 0.18 and 0.36 for $h^{2}$ w. The variation of both $h_{f}^{2}$ and $h^{2}{ }_{w}$ are large between species and trials, and for example $h_{f}^{2}$ of tank farmed sea bream is almost twice $h_{f}^{2}$ of marine feed sea bass. Our estimates for $h_{f}^{2}$ are in the usual range, which is comprised between $0.15 \pm 0.04$ and $0.52 \pm 0.06$ (Gjerde et al., 2012; Haffray et al., 2013, 2012, Kause et al., 2007, 2002; Navarro et al., 2009; Nguyen et al., 2010; Powell et al., 2008; Rutten et al., 2005b; Vandeputte et al., 2014). There is no reference value for $h^{2}{ }_{w}$, which is not reported in the existing literature.

The additive genetic and phenotypic correlations between fillet weight and waste weight were high in magnitude in our five fish batches $\left(r_{A}=0.91\right.$ and $r_{P}=0.88$ on average, see Table 3$)$. As expected however, correlations between fillet weight and waste weight were smaller than correlations between fillet weight and body weight $\left(r_{A}=0.987, r_{P}=0.981\right.$ on average). This was consistent with the literature where additive genetic correlations between fillet weight and body weight range from 0.93 to 0.99 , while phenotypic correlations range between 0.89 and 0.99 (Gjerde et al., 2012; Haffray et al., 2012; Kause et al., 2002; Navarro et al., 2009; Nguyen et al., 2010; Rutten et al., 2005a). Then, the parameters we used are representative of the parameters in different fish species where fillet yield was previously studied. However, as 
for heritability, we do not have reference values from the literature for genetic and phenotypic correlations between fillet weight and waste weight.

The high genetic and phenotypic correlations between body weight and fillet weight led some authors (Nguyen et al.,2010, in Nile tilapia; Powell et al.,2008 in Atlantic salmon) to conclude that fillet weight and body weight are controlled by the same set of genes. Powell et al. (2008) additionally used log-log regression to show that fillet weight is an almost constant proportion of body weight (in other words, that there is a linear relationship between body weight and fillet weight), and then inferred that selection on fillet yield was not possible. In our study, four fish populations out of five had a good (although low in absolute value) simulated response to selection on fillet yield $(+0.66 \%$ per generation on average). This was true even though the genetic and phenotypic correlations between fillet weight and body weight were very high, and the relationship between fillet weight and waste weight was linear (as they were simulated from a bivariate normal distribution). The lower gain in fillet yield for the marine-based feed sea bass population $(+0.39 \%$ per generation $)$ can be explained by the relatively low heritabilities of fillet weight and waste weight ( 0.23 and 0.18 respectively).

Simulated selection using fillet weight as an index was much less effective than selection on fillet yield in our five populations, as the mean predicted gain in fillet yield was $+0.29 \%$ per generation (range 0.17-0.50\%). This result is not in line with the predictions of Nguyen et al. (2010) who estimated that the predicted correlated response in fillet yield to selection for fillet weight in Nile tilapia was $0.59 \%$ per generation, and $0.57 \%$ per generation when fish were selected for body weight. In another study on Nile tilapia, Thodesen et al. (2012) found a genetic gain of fillet yield of $0.2 \%$ units per generation following selection for body weight, which is close to our mean estimate $(0.29 \%)$ using fillet weight as a selection index.

Following this study, we can recommend to estimate $h_{f}^{2}, h^{2}$, as well as $r_{A}$ and $r_{P}$ between fillet weight and waste weight in every new study about fillet yield, as these parameters are necessary to simulate or predict possible genetic gain on fillet yield. Still, real selection for yield traits may be more difficult than predicted by simulation.

One point of attention with the results of the present study is that not all combinations of parameters simulated may be realistic. Although for each individual parameter, we simulated values in the range observed from our real populations, combinations of parameters may be inconsistent with real situations. For example, situations where $r_{A}<r_{P}$ or where the heritabilities of fillet weight and waste weight are very different were never observed in any 
of our five fish batches. Nevertheless, simulated selection with the parameters of the five real fish populations significantly increased fillet yield, and in all five cases, direct selection on fillet yield was the best or second best method to improve fillet yield. Another point of caution is that in order to simplify the simulations, mass selection on the candidates' performance was simulated in most cases whereas in practice, selection is done using phenotypes from the candidates' siblings, as fillet yield is a lethal measurement. This choice was made because the precision of selection on the candidate's performances depends only on phenotypic and genetic parameters, whereas the precision of selection using information from sibs is also dependent on family structure (full and/or half sibs) and on the number of tested sibs per family (Falconer and Mackay, 1996). As we showed that selection indices in the five real populations ranked similarly when mass or sib selection was used, we considered that the advantage of simulating mass selection instead of sib selection outperformed its drawbacks.

Another final potential limitation to this study is the existence of a biological limit to select against waste weight, as no minimum waste weight was defined in the simulation model. We do not know how much waste weight can decrease without causing functional damage to the fish. For example, a study in poultry showed that selection on breast yield led to a decrease in lung volume (which is part of the waste in this case), that can cause health issues such as pulmonary hypertension and death (Sanchez et al., 2000). Similarly, a negative genetic correlation between fillet yield and the head and bone development was demonstrated in rainbow trout (Haffray et al., 2012). As head contains the respiratory and osmoregulatory organ (gills), and fragilized bones could lead to deformities, increasing fillet yield may be expected to lead to functional damage in the long term. This should be visible more rapidly in species with an already high fillet yield (salmon or trout) than in species with a lower fillet yield (sea bass, sea bream or Nile tilapia). However, although this issue of biological limits could be of high importance practically in the future, it is not expected to affect the validity of our results, at least when considering the first generations of selection. 


\section{Acknowledgements}

This work is part of the FishBoost project, funded by the European Union under the $7^{\text {th }}$ Framework Programme under grant agreement No 613611. We thank the fish breeding companies Ferme Marine du Douhet (FMD), Ecloserie Marine de Gravelines (EMG) and Sources de l'Avance for giving access to the data bases of slaughtering traits for the five fish population used in this study.

\section{References cited}

Acosta Alba, I., Aubin, J., Cariou, S., Haffray, P., Quittet, B., Vandeputte, M., 2015. Le programme FilDor: associer sélection génétique et analyse d'impact environnemental des élevages de poissons. Courr. Envir. INRA 65, 49-57.

Ankorion, Y., Moav, R., Wohlfarth, G.W., 1992. Bidirectionnal mass selection for body shape in common carp. Genet. Sel. Evol. 24, 43-52.

Besson, M., Komen, H., Aubin, J., De Boer, I.J.M., Poelman, M., Quillet, E., Vancoillie, C., Vandeputte, M., Van Arendonk, J.A., 2014. Economic values of growth and feed efficiency for fish farming in recirculating aquaculture system with density and nitrogen output limitations: A case study with African catfish (clarias gariepinus). J. Anim. Sci. 92, 5394-5405. doi:10.2527/jas2014-8266

Besson, M., Vandeputte, M., van Arendonk, J.A.M., Aubin, J., de Boer, I.J.M., Quillet, E., Komen, H., 2016. Influence of water temperature on the economic value of growth rate in fish farming: The case of sea bass (Dicentrarchus labrax) cage farming in the Mediterranean. Aquaculture 462, 47-55. doi:10.1016/j.aquaculture.2016.04.030

Bestin, A., Dupont-Nivet, M., Haffray, P., Médale, F., Quillet, E., Vandeputte, M., Cariou, S., Desgranges, A., Laureau, S., Ricoux, R., Beutin, C., 2014. Genotype by diet interactions on growth and processing traits in rainbow trout (Oncorhynchus mykiss), European sea bass (Dicentrarchus labrax), gilthead sea bream (Sparus aurata) and meagre (Argyrosomus regius) fed diets with almost complete substitution, in: Proceedings, 10th World Congress of Genetics Applied to Livestock Production.

Eisen, E.J., 1977. Restricted selection index: an approach to selecting for feed efficiency. J. Anim. Sci. 44, 958-972.

Falconer, D.S., Mackay, T.F.C., 1996. Introduction to quantitative genetics. Longman, Harlow, England. 
Famula, T.R., 1990. The equivalence of two linear methods for the improvement of traits expressed as ratios. Theor. Appl. Genet. 79, 853-856. doi:10.1007/BF00224256

Gjedrem, T., 2012. Genetic improvement for the development of efficient global aquaculture: A personal opinion review. Aquaculture 344-349, 12-22. doi:10.1016/j.aquaculture.2012.03.003

Gjerde, B., Mengistu, S.B., Ødegård, J., Johansen, H., Altamirano, D.S., 2012. Quantitative genetics of body weight, fillet weight and fillet yield in Nile tilapia (Oreochromis niloticus). Aquaculture 342-343, 117-124. doi:10.1016/j.aquaculture.2012.02.015

Gunsett, F.C., 1987. Merit of utilizing the heritability of a ratio to predict the genetic change of a ratio. J. Anim. Sci. 65, 936-942.

Gunsett, F.C., 1984. Linear Index Selection to Improve Traits Defined as Ratios. J. Anim. Sci. $59,1185-1193$.

Haffray, P., Bugeon, J., Pincent, C., Chapuis, H., Mazeiraud, E., Rossignol, M.N., Chatain, B., Vandeputte, M., Dupont-Nivet, M., 2012. Negative genetic correlations between production traits and head or bony tissues in large all-female rainbow trout (Oncorhynchus mykiss). Aquaculture 368-369, 145-152. doi:10.1016/j.aquaculture.2012.09.023

Haffray, P., Bugeon, J., Rivard, Q., Quittet, B., Puyo, S., Allamelou, J.M., Vandeputte, M., Dupont-Nivet, M., 2013. Genetic parameters of in-vivo prediction of carcass, head and fillet yields by internal ultrasound and 2D external imagery in large rainbow trout (Oncorhynchus mykiss). Aquaculture 410-411, 236-244. doi:10.1016/j.aquaculture.2013.06.016

Janssen, K., Berentsen, P., Besson, M., Komen, H., 2017. Derivation of economic values for production traits in aquaculture species. Genet. Sel. Evol. 49, 5. doi:10.1186/s12711016-0278-x

Kankainen, M., Setälä, J., Kause, A., Quinton, C., Airaksinen, S., Koskela, J., 2016. Economic values of supply chain productivity and quality traits calculated for a farmed European whitefish breeding program. Aquac. Econ. Manag. 20, 131-164. doi:10.1080/13657305.2016.1155961

Kause, A., Paananen, T., Ritola, O., Koskinen, H., 2007. Direct and indirect selection of visceral lipid weight, fillet weight, and fillet percentage in a rainbow trout breeding 
program. J. Anim. Sci. 85, 3218-3227.

Kause, A., Ritola, O., Paananen, T., Mantysaari, E., Eskelinen, U., 2002. Coupling body weight and its composition: a quantitative genetic analysis in rainbow trout. Aquaculture $211,65-79$.

Kempthorne, O., Nordskog, A.W., 1959. Restricted Selection Indices. Biometrics 15, 10-19.

Kennedy, B.W., van der Werf, J.H., Meuwissen, T.H., 1993. Genetic and statistical properties of residual feed intake. J. Anim. Sci. 71, 3239-3250.

Koerhuis, A.N.M., Hill, W.G., 1996. Predicted response in food conversion ratio for growth by selection on the ratio or on linear component traits, in a (sequential) selection programme. Br. Poult. Sci. 37, 317-327. doi:10.1080/00071669608417863

Lin, C.Y., 1980. Relative Efficiency of Selection Methods for Improvement of Feed Efficiency. J. Dairy Sci. 63, 491-494. doi:10.3168/jds.S0022-0302(80)82960-2

Lin, C.Y., Aggrey, S.E., 2013. Incorporation of economic values into the component traits of a ratio : Feed efficiency. Poult. Sci. 92, 916-922. doi:10.3382/ps.2012-02688

Lynch, M., Walsh, B., 1998. Genetics and analysis of quantitative traits. Sinauer Associates, Sunderland, MA.

Morley, F.W.H., 1955. Selection for economic characters in Australian Merino sheep. V. Further estimates of phenotypic and genetic parameters. Aust. J. Agric. Res. 6, 77-90.

Navarro, A., Zamorano, M.J., Hildebrandt, S., Ginès, R., Aguilera, C., Afonso, J.M., 2009. Estimates of heritabilities and genetic correlations for growth and carcass traits in gilthead seabream (Sparus auratus L.), under industrial conditions. Aquaculture 289, $225-230$.

Nguyen, N.H., Ponzoni, R.W., Abu-Bakar, K.R., Hamzah, A., Khaw, H.L., Yee, H.Y., 2010. Correlated response in fillet weight and yield to selection for increased harvest weight in genetically improved farmed tilapia (GIFT strain), Oreochromis niloticus. Aquaculture 305, 1-5. doi:10.1016/j.aquaculture.2010.04.007

Powell, J., White, I., Guy, D., Brotherstone, S., 2008. Genetic parameters of production traits in Atlantic salmon (Salmo salar). Aquaculture 274, 225-231.

Rutten, M.J.M., Bovenhuis, H., Komen, H., 2005a. Genetic parameters for fillet traits and body measurements in Nile tilapia (Oreochromis niloticus L.). Aquaculture 246, 125 
132.

Rutten, M.J.M., Komen, H., Bovenhuis, H., 2005b. Longitudinal genetic analysis of Nile tilapia (Oreochromis niloticus L.) body weight using a random regression model. Aquaculture 246, 101-113.

Sanchez, A., Plouzeau, M., Rault, P., Picard, M., 2000. Croissance musculaire et fonction cardio-respiratoire chez le poulet de chair. INRA Prod.Anim. 13, 37-45.

Thodesen, J., Rye, M., Wang, Y.-X., Bentsen, H.B., Gjedrem, T., 2012. Genetic improvement of tilapias in China: Genetic parameters and selection responses in fillet traits of Nile tilapia (Oreochromis niloticus) after six generations of multi-trait selection for growth and fillet yield. Aquaculture 366-367, 67-75. doi:10.1016/j.aquaculture.2012.08.028

Vandeputte, M., Garouste, R., Dupont-Nivet, M., Haffray, P., Vergnet, A., Chavanne, H., Laureau, S., Ron, T.B., Pagelson, G., Mazorra, C., Ricoux, R., Marques, P., Gameiro, M., Chatain, B., 2014. Multi-site evaluation of the rearing performances of 5 wild populations of European sea bass (Dicentrarchus labrax). Aquaculture 424-425, 239248.

Varkoohi, S., Moradi Shahr Babak, M., Pakdel, A., Nejati Javaremi, A., Zaghari, M., Kause, A., 2010. Response to selection for feed conversion ratio in Japanese quail. Poult. Sci. 89, 1590-1598. doi:10.3382/ps.2010-00744 
Tables

Table 1: Number of offspring and family structure, in five populations of fishes in three different species.

\begin{tabular}{lllll}
\hline Species & Batch & N fish & N sires & N dams \\
& & & \\
\hline Sea bass & Plant-based feed & 857 & 45 & 15 \\
& & & & \\
\cline { 2 - 5 } & Marine feed & 857 & 45 & 15 \\
\hline Sea bream & cage farmed & 1987 & 82 & 26 \\
\cline { 2 - 5 } & tank farmed & 2000 & 82 & 61 \\
\hline Rainbow trout & & 2042 & 101 & \\
\hline
\end{tabular}


Table 2: Range (minimum, maximum, step) of parameters tested in the selection simulations. $\mathrm{h}^{2} \mathrm{f}$ : heritability of fillet weight, $\mathrm{h}_{\mathrm{w}}{ }_{\mathrm{w}}$ : heritability of waste weight, $\mathrm{r}_{\mathrm{A}}$ : genetic correlation of fillet and waste weight, $\mathrm{r}_{\mathrm{P}}$ : genetic correlation of fillet and waste weight, $\mathrm{CV}_{\mathrm{f}}=$ coefficient of variation of fillet weight, $C V_{w}=$ coefficient of variation of waste weight, $\mu_{f} /\left(\mu_{w}+\mu_{f}\right)$ : mean fillet yield

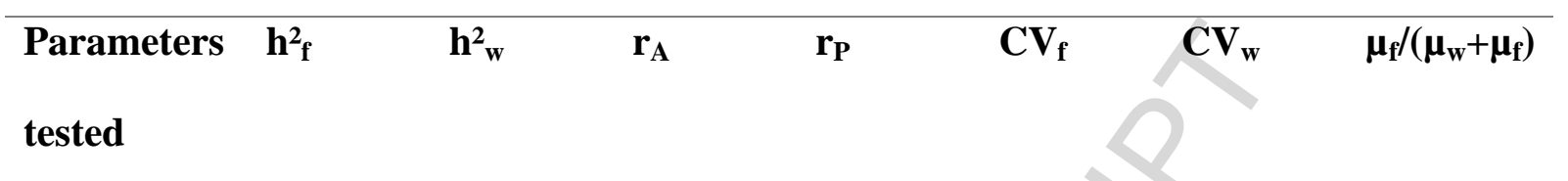

\begin{tabular}{lccccccc}
\hline $\begin{array}{l}\text { Minimal } \\
\text { value }\end{array}$ & 0.20 & 0.15 & 0.84 & 0.80 & $10 \%$ & $10 \%$ & 0.54 \\
\hline $\begin{array}{l}\text { Maximal } \\
\text { value }\end{array}$ & 0.45 & 0.40 & 0.98 & 0.96 & $30 \%$ & $30 \%$ & 0.66 \\
\hline Step & & & & & & & \\
\end{tabular}

five batches 


\section{Table 3}

Estimated values of phenotypic and genetic parameters ( \pm standard error), of fillet (f subscript) and waste (w subscript) weight in five batches of three fish species, heritabilities $\left(h^{2}\right)$ additive genetic $\left(r_{A}\right)$ and phenotypic $\left(r_{P}\right)$ correlations between fillet weight and waste weight, Coefficient of variation $(\mathrm{CV})$, mean.

\begin{tabular}{|c|c|c|c|c|c|c|c|c|c|c|}
\hline Species & Batch & $\mathbf{h}^{2} \mathbf{f}$ & $\mathbf{h}^{2}{ }_{w}$ & $\mathbf{r}_{\mathrm{A}}$ & $\mathbf{r}_{\mathbf{P}}$ & $\mathbf{C V}_{\mathrm{f}}$ & $\mathbf{C V}_{\mathrm{w}}$ & $\begin{array}{l}\text { Mean } \\
\text { fillet } \\
\text { weight } \\
\text { (g) }\end{array}$ & $\begin{array}{l}\text { Mean } \\
\text { waste } \\
\text { weight } \\
\text { (g) }\end{array}$ & $\begin{array}{c}\text { Mean } \\
\text { fillet } \\
\text { yield } \\
\text { (g fillet/g BW) }\end{array}$ \\
\hline \multirow[t]{2}{*}{ Sea bass } & Plant-based feed & $0.41 \pm 0.09$ & $0.36 \pm 0.08$ & $0.94 \pm 0.02$ & 0.92 & $30 \%$ & $27 \%$ & 412 & 322 & 0.56 \\
\hline & Marine feed & $0.23 \pm 0.07$ & $0.18 \pm 0.06$ & $0.93 \pm 0.04$ & 0.86 & $22 \%$ & $23 \%$ & 496 & 373 & 0.57 \\
\hline \multirow[t]{2}{*}{ Sea bream } & Cage farmed & $0.32 \pm 0.06$ & $0.34 \pm 0.06$ & $0.90 \pm 0.03$ & 0.87 & $19 \%$ & $16 \%$ & 230 & 152 & 0.60 \\
\hline & Tank farmed & $0.42 \pm 0.06$ & $0.35 \pm 0.06$ & $0.87 \pm 0.03$ & 0.82 & $15 \%$ & $14 \%$ & 188 & 133 & 0.58 \\
\hline Rainbow trout & & $0.34 \pm 0.05$ & $0.35 \pm 0.05$ & $0.93 \pm 0.02$ & 0.93 & $23 \%$ & $21 \%$ & 1047 & 575 & 0.64 \\
\hline Average & 1 & 0.34 & 0.32 & 0.91 & 0.88 & $22 \%$ & $20 \%$ & 475 & 311 & 0.59 \\
\hline
\end{tabular}




\section{Figure Captions}

Figure 1. Ten generations simulated gain in fillet yield (mean \pm standard deviation) with an average set of genetic and phenotypic parameters at the mean value of those of the real populations (see Table 2) under different selection indices... Mass selection; . . ...sib selection

Figure 2. Ten generations simulated gain in fillet yield (mean \pm standard deviation) for different values of fillet yield in $\mathrm{G}_{0}$ when the other parameters are fixed at the mean of the five batches and under two methods of selection: selection with the linear index (IL) or direct selection on fillet yield (IY)

Figure 3. Ten generations simulated gain in fillet yield (mean \pm standard deviation) for different combinations of heritabilities of fillet weight and waste weight when the other parameters are fixed at the mean of the five batches and under two methods of selection a. direct selection on fillet yield, b. selection on linear index

Figure 4. Ten generations gain in fillet yield (mean \pm standard deviation) for different combinations of additive genetic $\left(\mathrm{r}_{\mathrm{A}}\right)$ and phenotypic $\left(\mathrm{r}_{\mathrm{P}}\right)$ correlations between fillet weight and waste weightwhen the other parameters are fixed at the mean of the five batches and under two methods of selection a. direct selection on fillet yield, b. selection on linear index.

Figure 5. Ten generations gain in fillet yield (mean \pm standard deviation) for different combinations of coefficient of variation (CV) of fillet weight and waste weight when the other parameters are fixed at the mean of the five batches and under two methods of selection a. direct selection on fillet yield, b. selection on linear index 


\section{Figures}

\section{Figure 1}

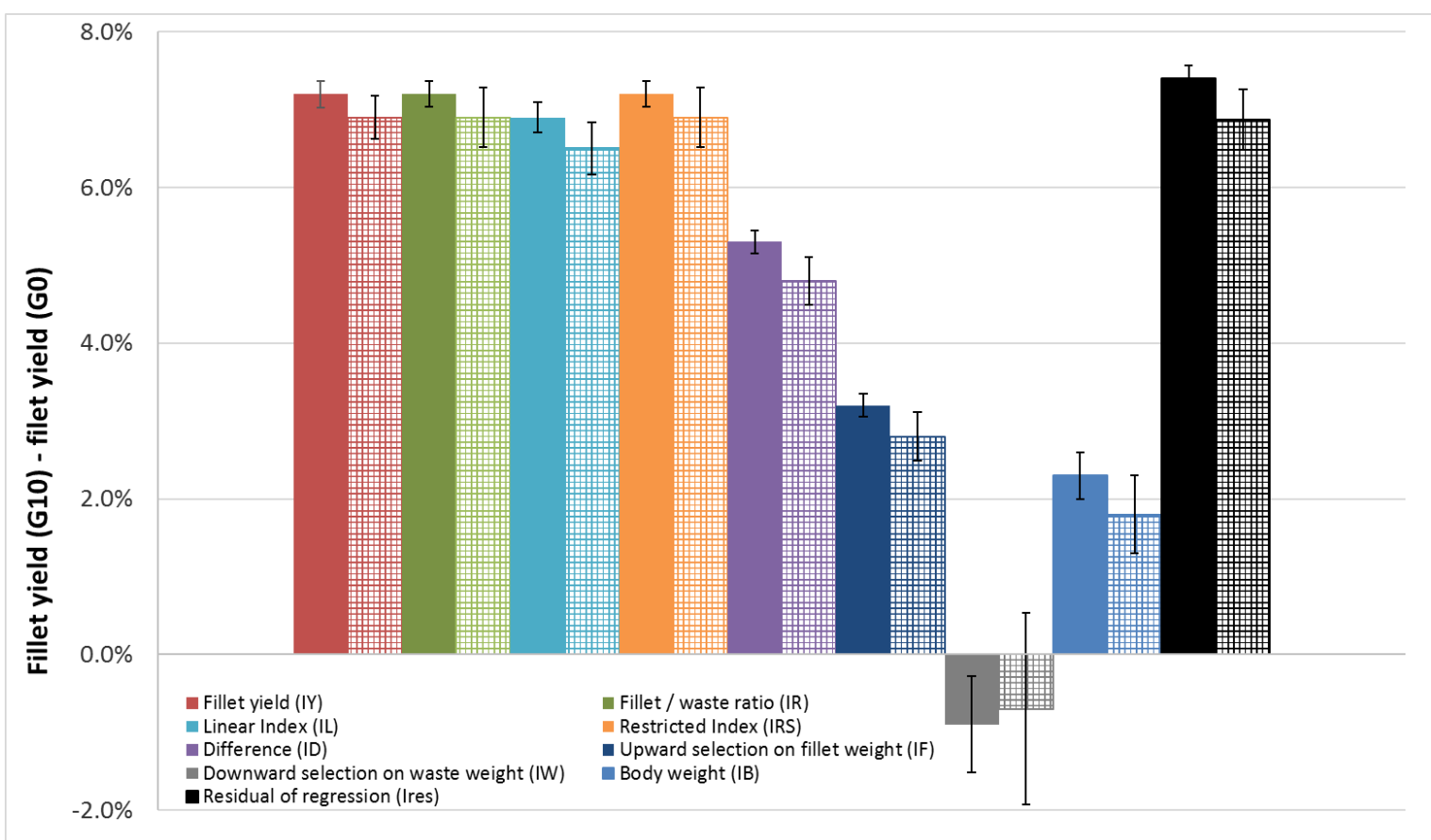

\section{Figure 2}

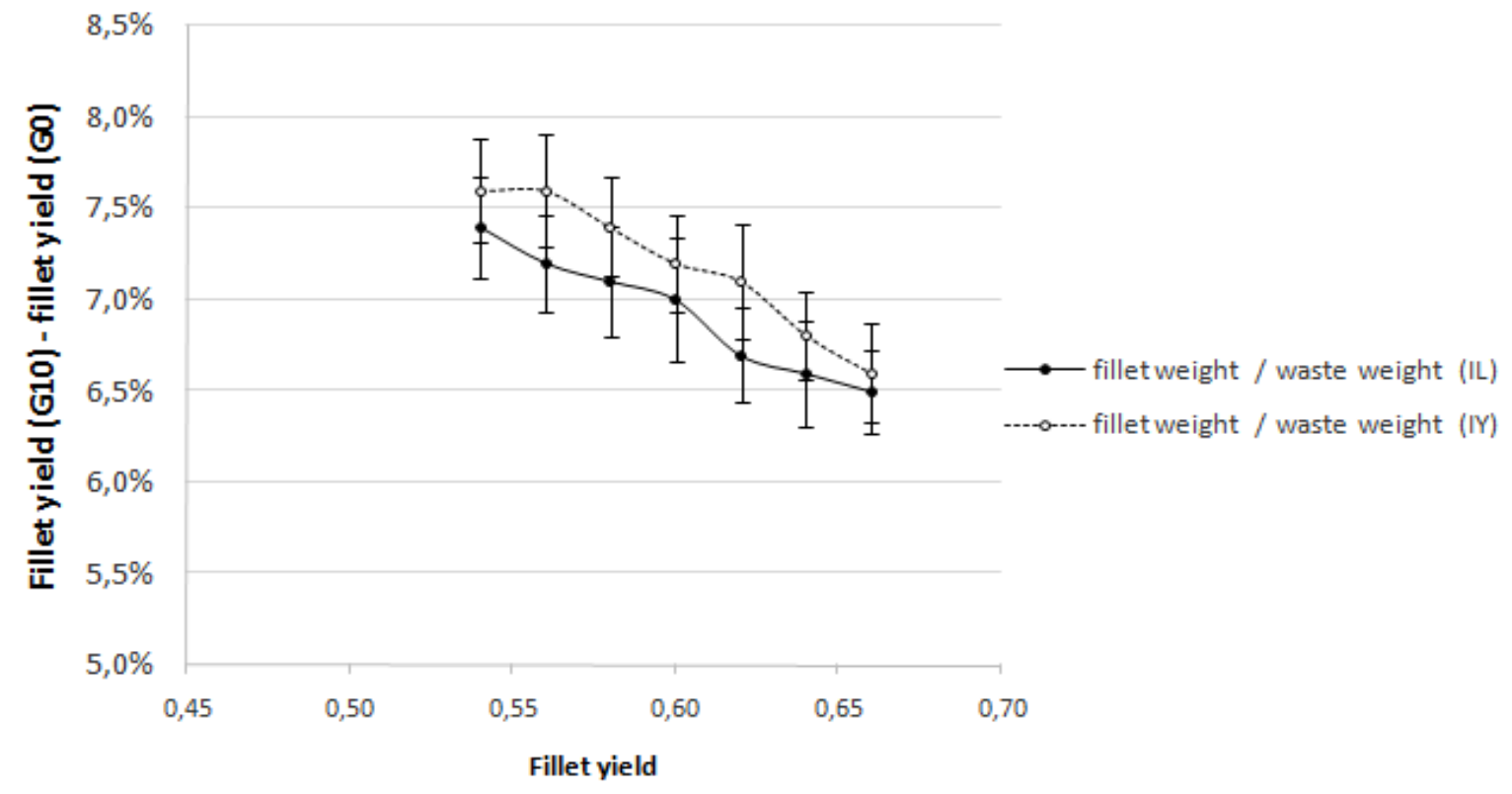




\section{Figure 3}

a.

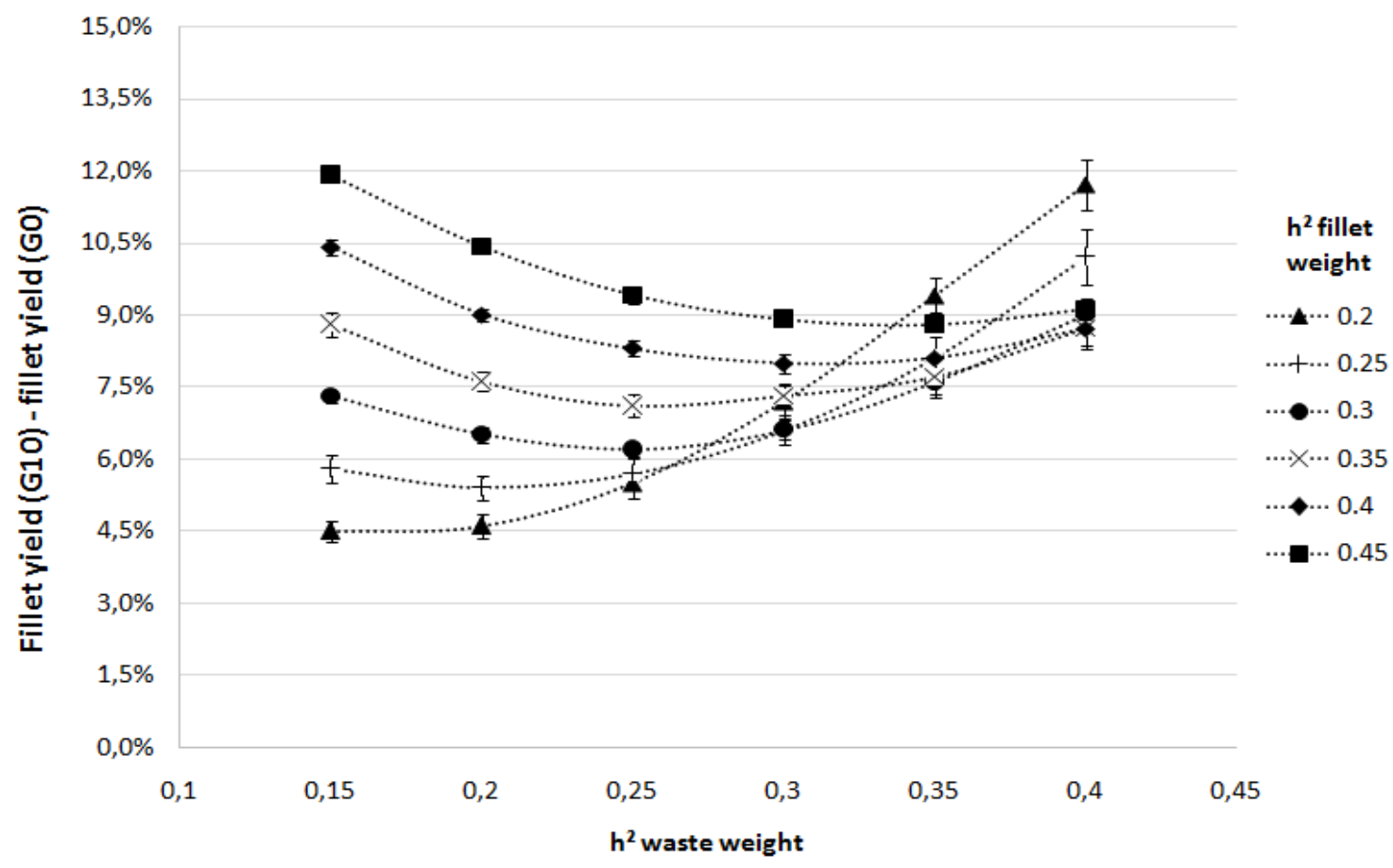

b.

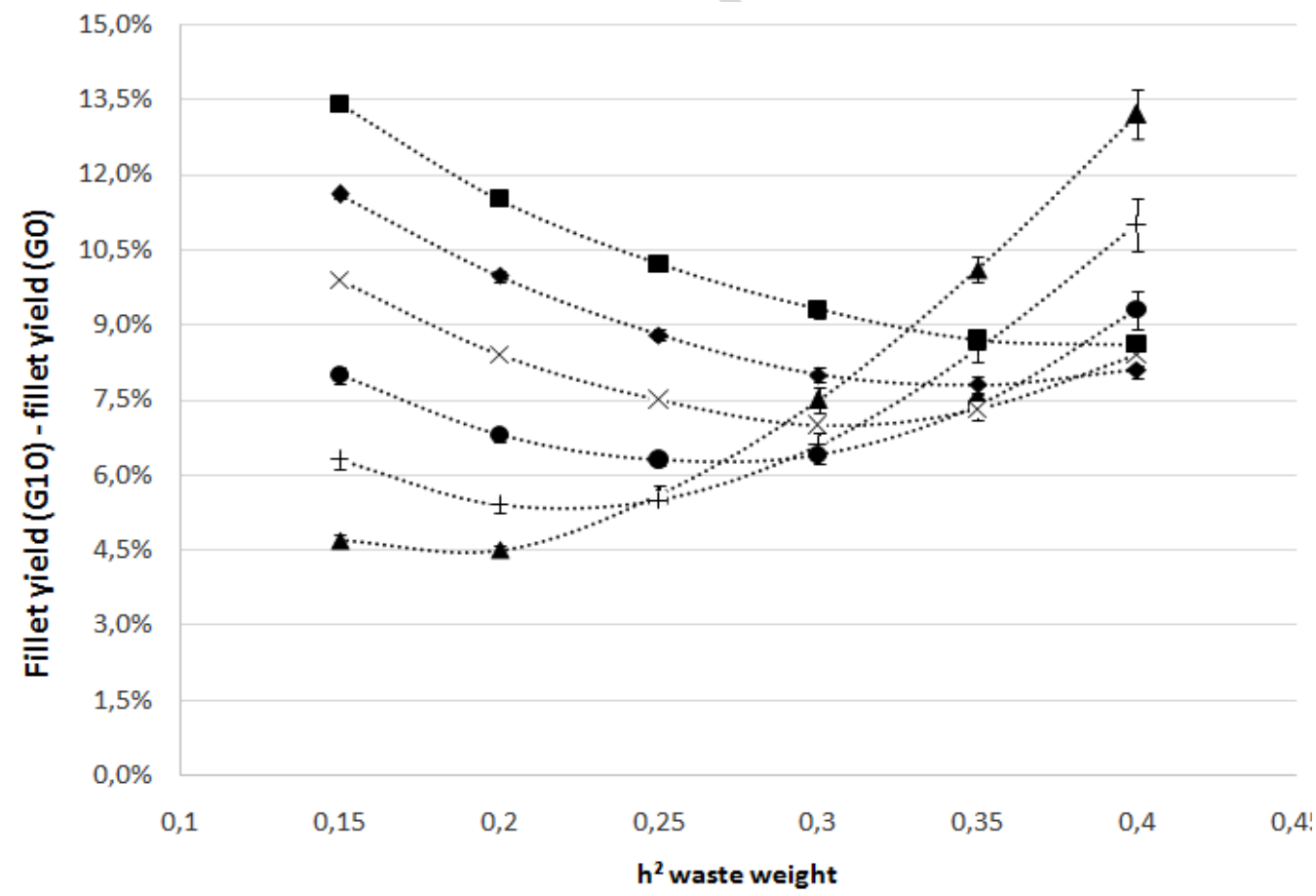


Figure 4

a.

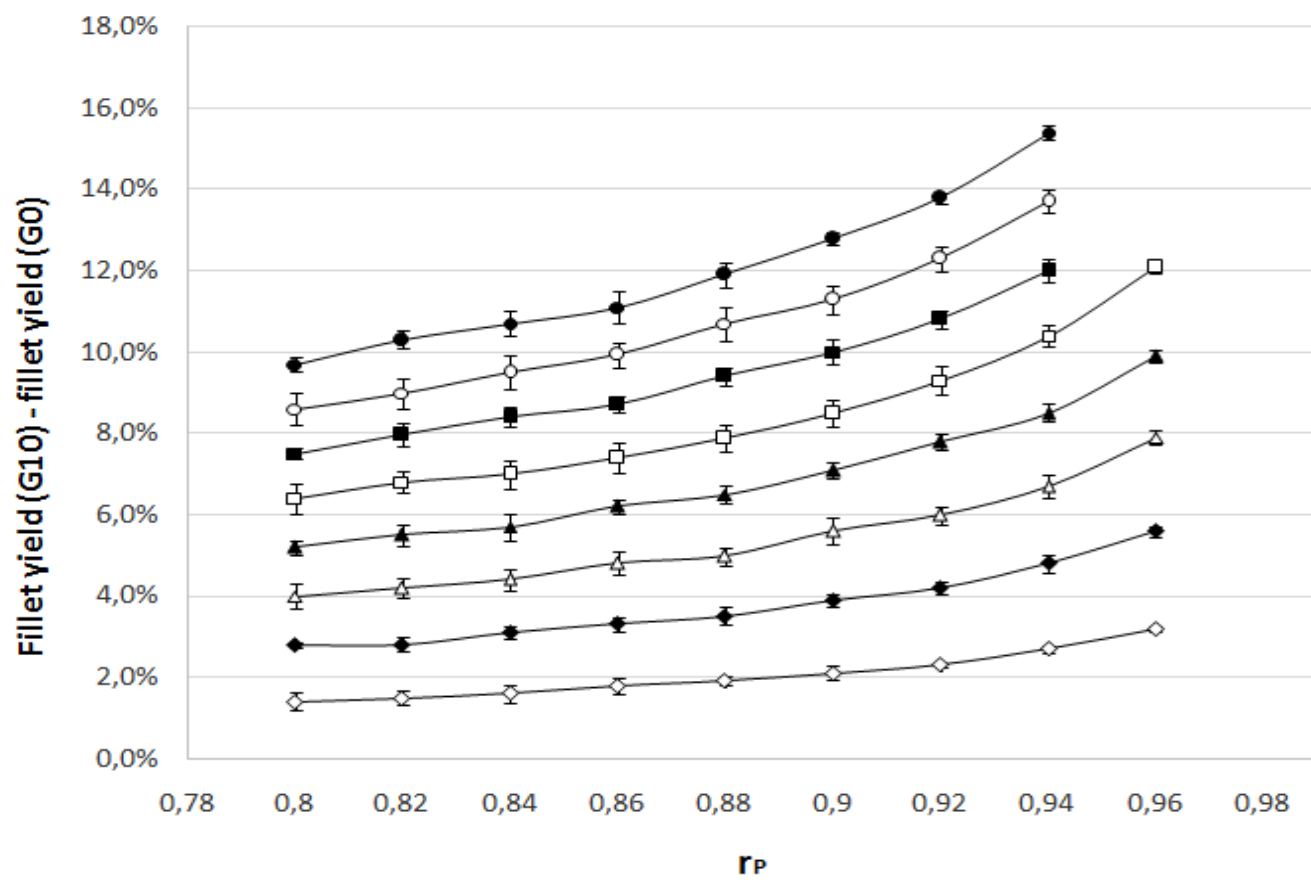

b.

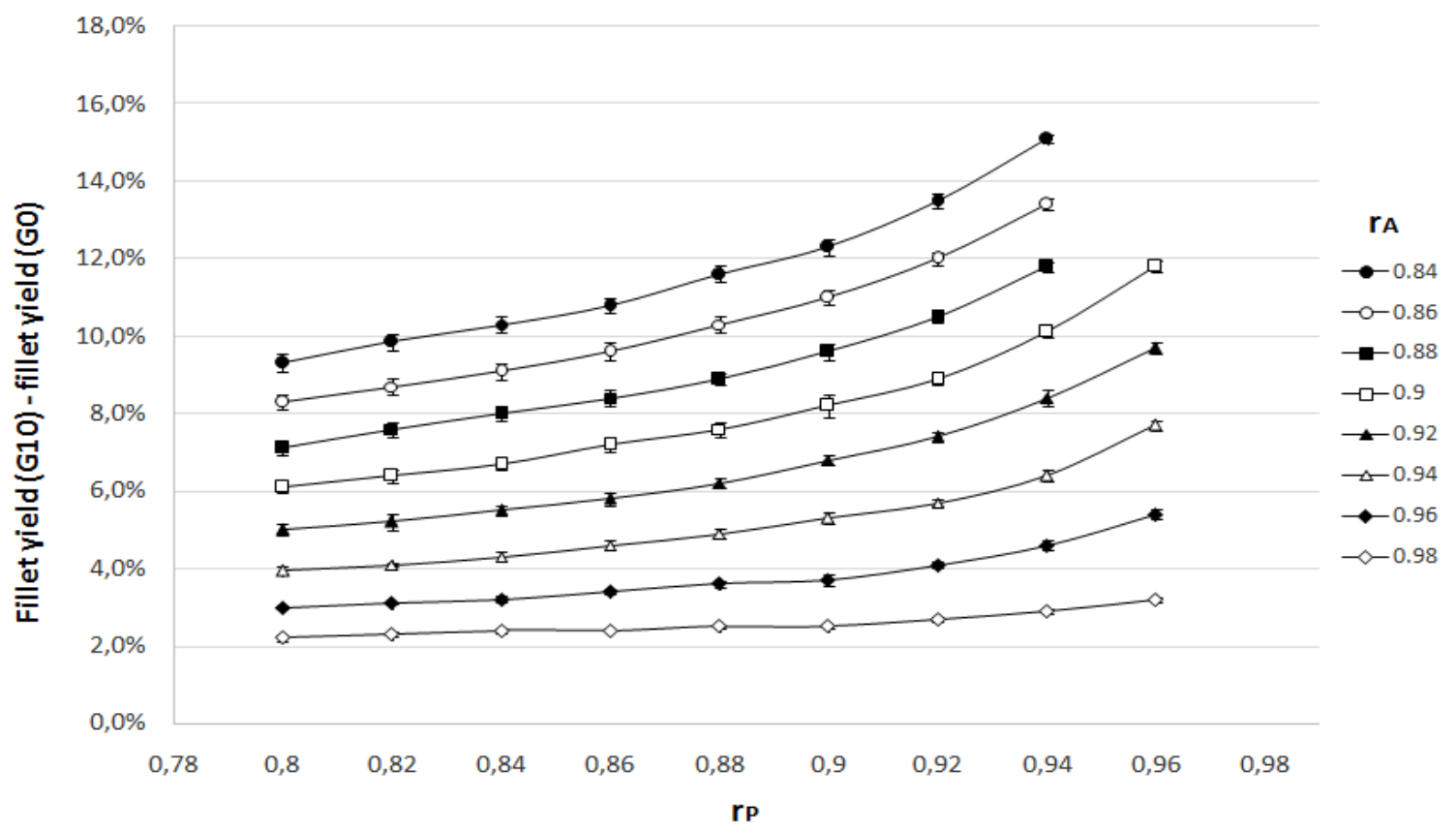


Figure 5

a.

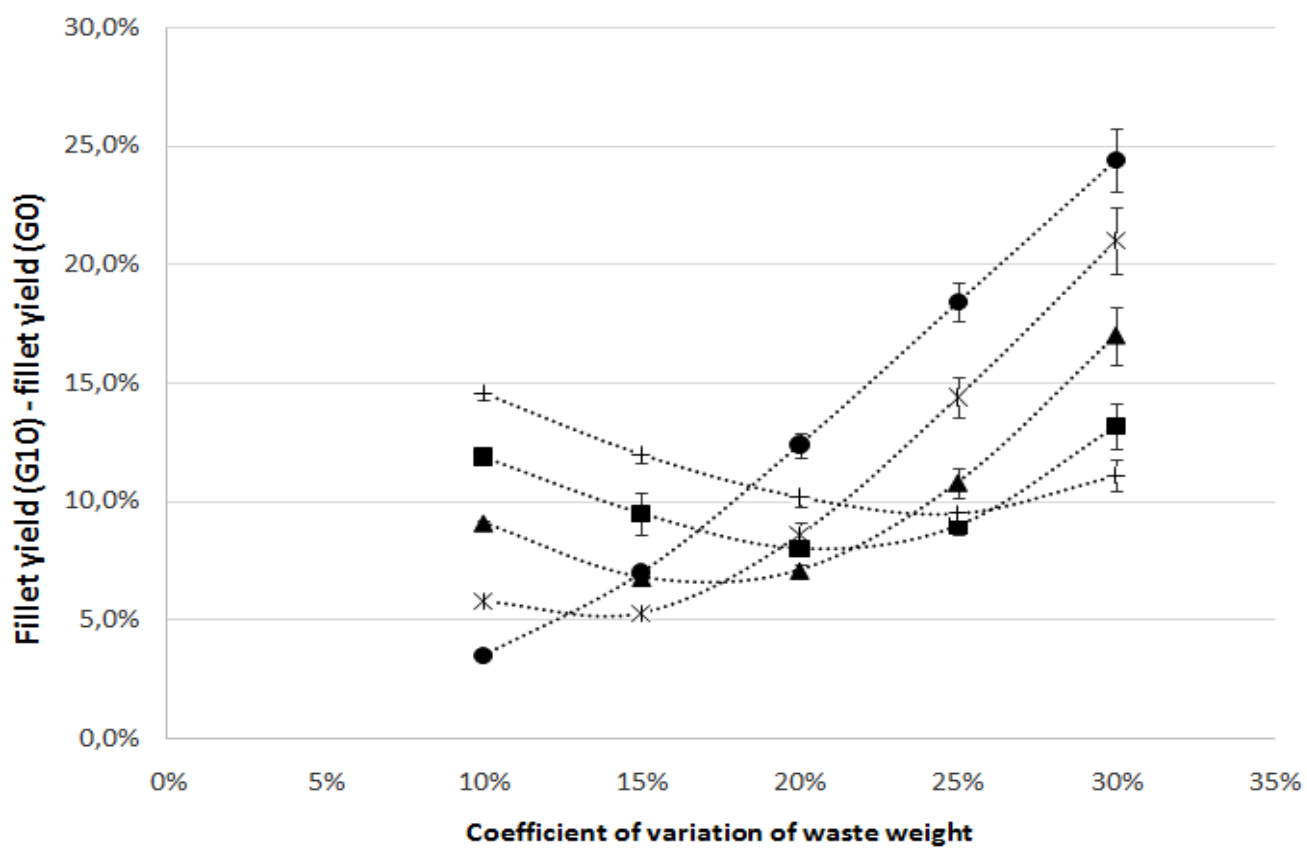

b.

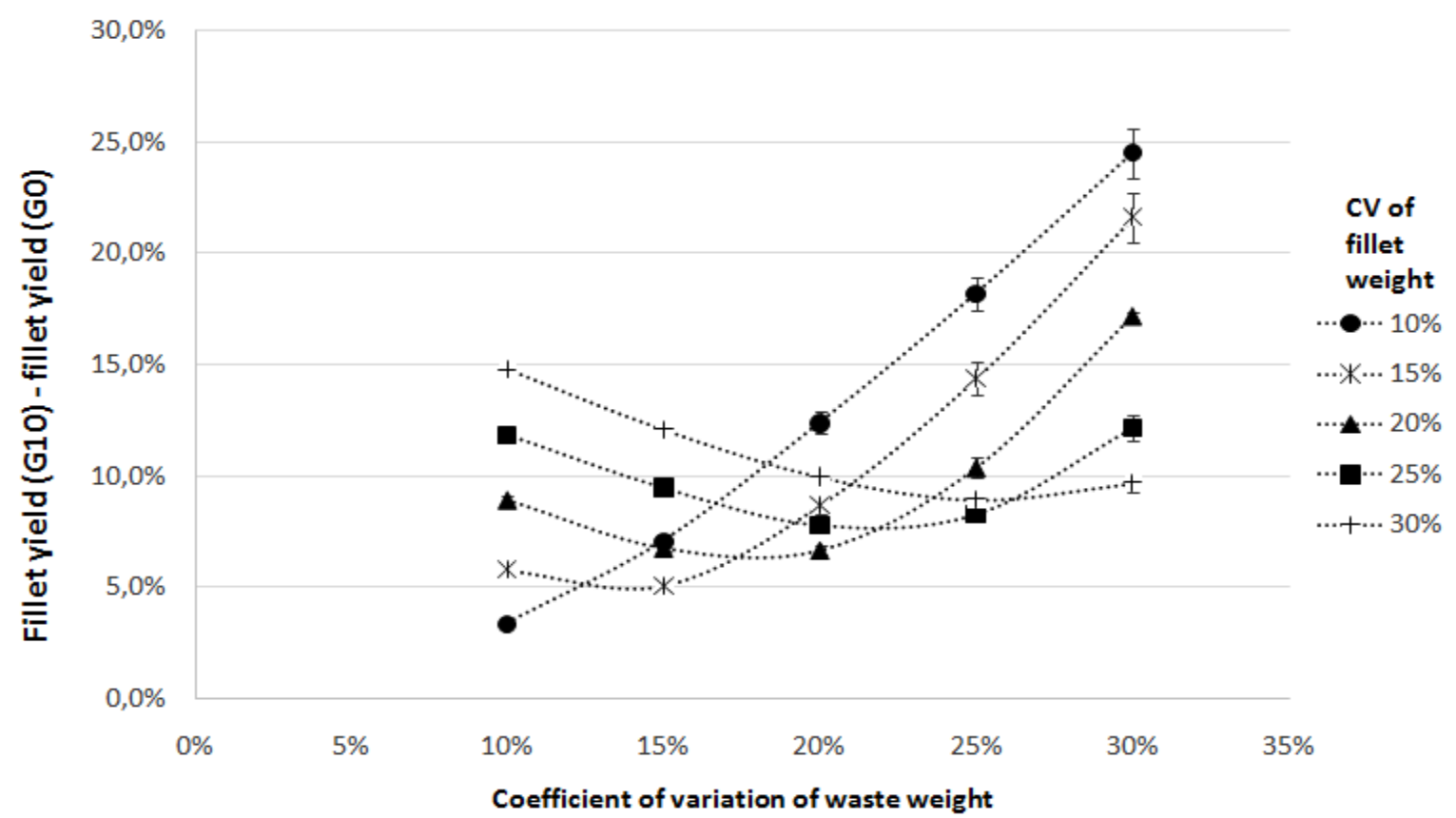


Highlights

We estimated genetic parameters of fillet weight and waste weight in fish

We performed stochastic simulations to evaluate gains in fillet yield

Fillet yield can be improved by $0.66 \%$ per generation on average in simulations

Fillet yield, fillet/waste ratio and fillet weight to body weight residuals are good selection indices

Selection for fillet weight or body weight performed poorly to improve fillet yield 